\title{
Artificial Intelligent Tuning PI Controller on Wind Turbine System with Three-Phase Grid Connected System
}

\author{
Wipobh Jaikhang ${ }^{1}$, Satean Tunyasrirut ${ }^{2}$ \\ ${ }^{1,2}$ Graduate of Electrical Engineering, Faculty of Engineering, Pathumwan Institute of Technology, Bangkok, Thailand
}

\begin{tabular}{l} 
Article Info \\
\hline Article history: \\
Received May18, 2019 \\
Revised Dec 4, 2019 \\
Accepted Dec 20, 2019 \\
\hline Keywords: \\
Artificial intelligent tuning \\
PI controller \\
Wind turbine \\
Grid connected \\
Three-phase
\end{tabular}

\section{Corresponding Author:}

Satean Tunyasrirut,

Graduate of Electrical Engineering, Faculty of Engineering,

Pathumwan Institute of Technology,

833 Rama 1 Rd., Wangmai, Pathumwan, Bangkok, 10330, Thailand.

Email: satean2000@gmail.com

\begin{abstract}
In order to generate the electricity from the wind turbine system with a permanent magnet synchronous generator (PMSG) to the three-phase grid connected system, it is very challenging because the electricity generated from wind energy resource is inconstancy. In this paper, the electrical power between the two systems are regulated by PI controller. For tuning the gains of PI controller, artificial intelligent methods, particle swarm optimization (PSO), gravitational search algorithm (GSA), artificial neural networks (ANN), are applied. The experiments of the control systems are testing at 200 $\mathrm{w}$ and $400 \mathrm{w}$. The experimental results show that the rise time of an electrical power of control system at $200 \mathrm{w}$ tuning gains of the PI controller by ANN combined with PSO is better than the traditional tuning methods, pole placement. Therefore, the proposed intelligent system can not only reduce the overshoot of the active power but also improve the response power.
\end{abstract}

Copyright $(2019$ Institute of Advanced Engineering and Science. All rights reserved.

\section{INTRODUCTION}

In the present, the world economy has been rapidly developed. The business, industry, and service have been continuously growing. The demand of electricity for the economic activities such as production, consumption, and distribution and etc., is exploded. The generating electricity have been recently researched for each country in order to supply electricity for supporting the household section and economic activities. Thus, the electricity plays an important role in human life and country development. The energy of generating electricity can be classified into two categories. Firstly, fuel energy consists of fossil fuel energy and coal energy. Secondly, natural energy is an alternative energy from water, wind, and solar resources. One implication of resource-based perspective is that fossil fuels are probably running out. The natural energy, friendly to the environment is the reform replaced. Since, it is renewable and clean energy [1-2]. Moreover, a renewable energy technology has been researched, continuously. One of the natural resources are wind, clean, green, and sustainable energy, derived from the temperature difference. Obviously, a wind energy is applied to produce electricity generated from the conversion of kinetic energy to mechanical energy. Despite the fact that the wind energy in Thailand is inconsistent in each season due to the difference of the temperature, pressure, and centrifugal force of the earth's rotation. These factors affect the electricity generation. In changing kinetic energy to electrical energy, wind turbine is operated. It spins a generator to create electricity [3]. In Thailand, $50 \mathrm{~Hz}$ frequency of low voltage system can be divided into two systems, namely, 220 volts with single-phase voltage grid system and 380 volts with three phase voltage grid system. The electricity generated by a wind turbine is linked to the three-phase voltage grid system of provincial electricity authority (PEA). However, the amount of electricity is unstable because of the inconsistency of wind energy in a season. The electrical voltage from power supply connected to the three-phase voltage is required the control system. In a control system, PI controller, a proportional-integral-derivative controller, is a control loop feedback. By adjusting the PI constant or gain values, the controller is able to regulate pattern for the plant process. However, the PI controller does 
not guarantee that a control system is optimal or that the process is may be stable. The gains can be tuned by various methods such as pole placement, Ziegler-Nichols which are the static and traditional approaches. In modern control, a metaheuristic optimization method as the intelligent methods has currently evolved to optimize the gain values. The research papers had been studied the optimization techniques for controlling the gain values of the PI controller in the following several aspects. The inconsistency of wind speed in wind turbine associated with the grid system occurred in the electricity generation. Controlling synchronous speed to provide the grid system through inverter was adapted by Fuzzy-PI controller. The simulation of this experiment was modelled to increase the efficiency of performance on MATLAB/Simulink [4]. The optimization based on ACO on tuning parameters of the PI controller for compensating voltage in balanced condition applying to current harmonics and compensate reactive electric power. Two methods were controlled in a different. Shunt active power filter (SAPF) was depended on a conventional PI controller and using ant colony optimization for PI controller, which are based on $P-Q$ theory to produce the appropriate current reference signals. The results from MATLAB/Simulink power system toolbox showed that ant colony PI controller could reduce the disturbed harmonic and also compensate reactive electric power. The efficiency of permanent magnet generators (PMGs) and converter of power electronics in case of small scale wind energy. Variable magnitude and variable frequency of PMG were proposed in a constant direct current by implementing a full bridge rectifier and closed loop boost converter [5-7]. A $P-Q$ theory based on Clark's transform to improve PI controller. MATLAB/Simulink was a tool for simulation of the control system to optimize parameter from the grid-interfacing inverter. The inverter was connected to three- phase three wire system in order to be a multifunctional device operating with active magnet [8]. Designed the controller and active energy filter of LCL filter-based shunt active power filter (SAPF) which effectively compensated harmonic current. The designed devices were utilized to a nonlinear load in three-phase three wire with LCL filter by adding output SAPF. The filter based on passive process could more reduce the harmonic. PI and Fuzzy Controllers in MATLAB/Simulink were used to extract the three-phase reference currents for shunt active power filters for both $P-Q$ and id-iq control strategies under different main voltages, balanced, unbalanced, balanced and non-sinusoidal. The result shows that the fuzzy logic controller provides the better performance than the PI controller in any voltage conditions [9]. As referred to control system, the $P-Q$ theory, PI controller, fuzzy logic controller and so on, those have proven to be very efficient and practical. However, they are traditional control methods which are very concreted idea. In recent year, an intelligent control is playing an important role for tuning the controllers. PSO and GSA, metaheuristics based on nature-inspired algorithms, are applied to tuning the gains of the controller, the application of particle swarm optimization (PSO) to tune the control parameters of VSC stations under multi-objective optimization of VSC stations in multi-terminal VSC-HVdc grids. In the steady state and dynamic control performances, the results are presented that both classical and PSO-based can tune the parameters, under the condition load demand change from ac grids, wind power change, and permanent VSC disconnection [10]. Fernando M. de Oliveira et al. [11] used the PSO based on maximum power point tracking (MPPT) technique to solve problems related to mismatching phenomena of grid-tied photovoltaic system. In order to avoid over the power rating of the gridtied inverter, the PV system has the current generator controls for the energy processed, because of the active power injected into the grid, reactive power compensation and harmonic current suppression completes, concurrently. In simulation and experimental results, the performance and feasibility of the grid-tied PV system are calculated. Mariammal Thirumeni et al. [12] the design and analysis the hybrid particle swarm optimization and gravitational search algorithm (PSO-GSA) to tune PI and SMC controller for DC-DC Cuk converter. The PSO-GSA technique is able to tune the proportional and integral gains. Alessandro Massi Pavan et al. [13] proposed ANN based grid voltage and frequency forecaster for the forecasting of the voltage and the frequency at the point of connection between a battery energy storage system. At the University of Manchester and the local low-voltage distribution grid, the systems are installed. As a real-time controller for optimal management of the storage system, the techniques are able to be applied. This study is implemented in a dSPACE-based real-time controller. Safdar Raza et al. [14] used evolutionary programming (EP) and PSO for updating the weights of ANN in the hidden layer for the islanding detection technique employed minimal features of the power system. The simulation results express that the proposed technique is able to distinguish islanding from other non-islanding. Ali Muhtar et al. [15] compare the performance of ANN and ANN-PSO as learning algorithm to track MPP in PV system. The result, the average value of power generated from PV system, showed that ANN using PSO is better than ANN.

On the whole, the literature reviews found that PSO and gravitational search algorithm (GSA) can be combined as a hybrid algorithm for tuning the parameters of PI controller. Consequently, this research proposed tuning methods for controlling the PI controller of PMSG wind turbine depending on the different wind speeds. The electric power is controlled and flowed into three-phase voltage grid system of PEA of Thailand. On the other hand, the capacity of control system is based on $200 \mathrm{w}$ and $400 \mathrm{w}$ on electrical power with no load. The tuning of PI controllers will be operated by conventional methods, pole placement and five metaheuristic 
optimization techniques. The results are compared among pole placement, particle swarm optimization (PSO), gravitational search algorithm (GSA), artificial neural networks, the combination of neural networks and particle swarm optimization, and the combination of neural networks and gravitational search algorithms. The effectiveness of the conventional method and five metaheuristic optimization techniques is based on the minimum value of mean square error (MSE).

\section{PROPOSED SYSTEM}

As shown in Figure 1, it shows the connection between external wind energy supply of wind turbine and PMSG. The alternating current is produced by the rectifier, transformed to the direct current. The constant level of electric voltage is controlled by PI controller consisting of the digital signal processor for controlling pulse width modulation control (PWM) to the inverter by using the transformation of direct current voltage to alternating current voltage onto impedance of voltage transmission line. The parameters and the standard frequency of PEA of Thailand are given at 380 volts and $50 \mathrm{~Hz}$, respectively. Then, the electric power is transmitted to the grid system of PEA of Thailand. The voltage from the grid system can feedback to the inverter system as well. In case of lacking of wind energy, the principle of voltage transformation from threephrases to two-phrases are based on the Clarke's transformation theory. Besides, the $P$ - $Q$ theory is adopted to analyze the PI controller for controlling reference and real current through hysteresis controller in order to switch the operation when the response less than and equal to the reference signal. Based on inverse Clarke's transformation theory, driven circuit will drive the gate for working out in case of transformation of two-phase to three-phase voltages.

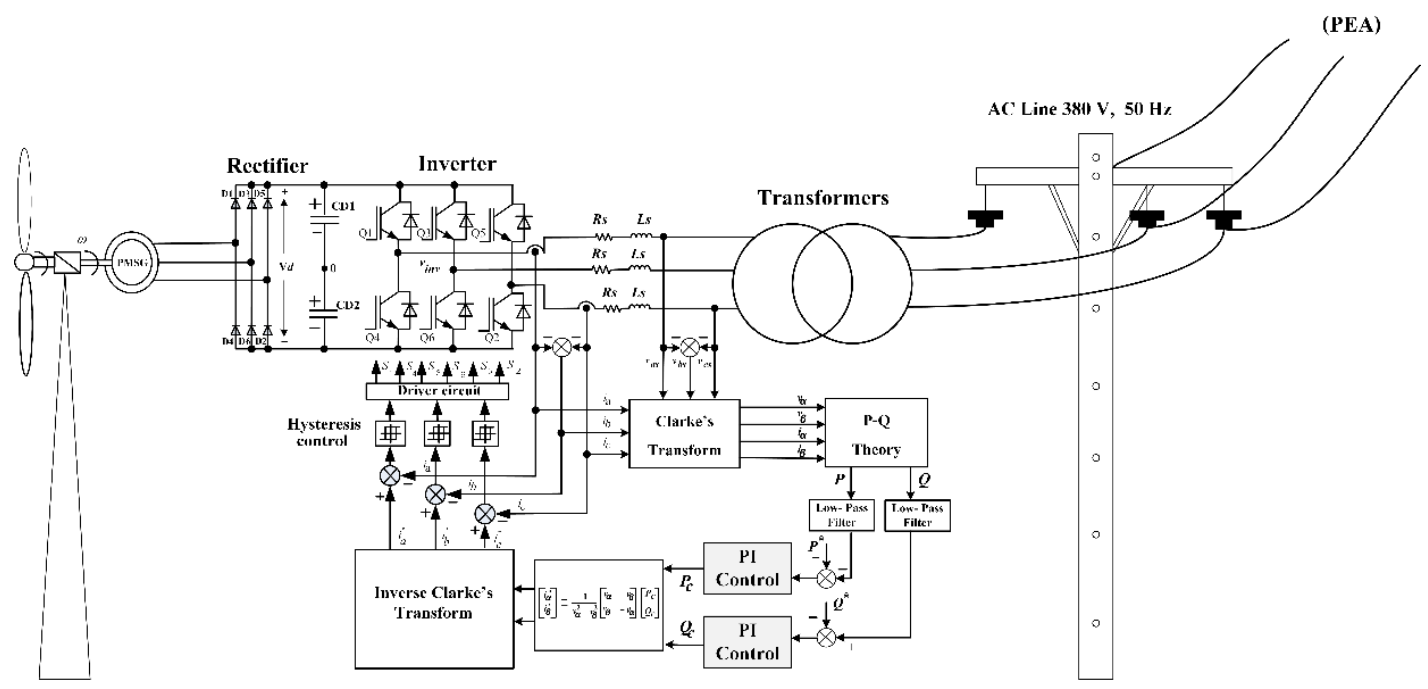

Figure 1. Scheme of wind turbine based on PMSG generator connected to the grid system

\section{1. $P-Q$ theory}

The $P-Q$ theory based on Clarke transformation that composes a real matrix to transform the threephase voltages and currents into the $\alpha-\beta$ stationary reference frame, is widely applied to the control system [16]. The voltage and current parameters of the two-phases are carried out by using stationary reference frames. This theory is derived from the power of electricity $P$ and $Q$. It can be written as the following (1) and (2), respectively.

$$
\begin{aligned}
& P=\left(v_{\alpha} i_{\alpha}+v_{\beta} i_{\beta}\right) \\
& Q=\left(v_{\alpha} i_{\beta}-v_{\beta} i_{\alpha}\right)
\end{aligned}
$$

Consequently, an appearance power can be written as

$$
S=v i^{*}=(P \pm j Q)
$$

where $S$ is an appearance power, $v$ is a voltage, $\alpha-\beta$ are the reference frames, $i^{*}$ is a complex conjugate of current, and $j$ is an imaginary part of a complex variable which consists of a real part and imaginary part as follows.

$$
S=\left(v_{\alpha} i_{\alpha}+v_{\beta} i_{\beta}\right) \pm j\left(v_{\beta} i_{\alpha}+v_{\alpha} i_{\beta}\right)
$$

where $P$ is the real part, $Q$ is the imaginary part.

$P-Q$ theory can be written as the product of the matrix form of voltage matrix and current matrix as in (5). 


$$
\left[\begin{array}{l}
P \\
Q
\end{array}\right]=\left[\begin{array}{cc}
v_{\alpha} & v_{\beta} \\
-v_{\beta} & v_{\alpha}
\end{array}\right]\left[\begin{array}{l}
i_{\alpha} \\
i_{\beta}
\end{array}\right]
$$

The application of Clarke's transformation in a control system is that the vector parameters as threephase voltages, $v_{a s}, v_{b s}, v_{c s}$ are transformed to two-phase voltages, $v_{a s}, v_{\beta s}$. The different angle between the vector of the three-phases and two-phase voltage is an electrical degree of 90 . Then, two-phase voltages are transformed to the direct voltages, $v_{\alpha e}, v_{\beta e}$. The three-phase currents, $i_{a s}, i_{b s}, i_{c s}$ are transformed to the alternating current with two-phase current, $i_{\alpha s}, i_{\beta s}$, with an electrical degree of 90 . Then, the two-phase current are transformed to alternating current, $i_{\alpha e}, i_{\beta e}$. The transformation of the stationary reference frame of three-phase system, $a, b$ and $c$, to two-phase system, $\alpha-\beta$ is called Clarke's transformation presented by Edith Clarke, who is an American electrical engineer. The transformation of stationary reference frame [17-18] in which the threephase system, $a, b$ and $c$ consists of voltages, $v_{a s}, v_{b s}$ and $v_{c s}$. The voltage vector angles are at 120 electrical degrees of each other. Thus, the phase of the voltage with angular velocity is given as the following [19].

$$
\begin{aligned}
& v_{a s}(t)=v_{a s} \cos (\omega t) \\
& v_{b s}(t)=v_{b s} \cos \left(\omega t-120^{\circ}\right) \\
& v_{c s}(t)=v_{c s} \cos \left(\omega t+120^{\circ}\right)
\end{aligned}
$$

where $\omega$ is an angular velocity of red per second unit. The vector space of voltage, $v_{s}(t)$ at a time $t$ can be a linear combination of the three phases of sinusoidal voltage functions which form the complex variable. Thus, the equation of voltage vector space is given as

$$
v_{s}(t)=v_{a s}(t)+v_{b s}(t) e^{j 2 \pi / 3}+v_{c s}(t) e^{j 4 \pi / 3}
$$

where $e^{j \theta}=\cos \theta+j \sin \theta$. Substituting of (1) into (2), the voltage vector space is shown in (8).

$$
v_{s}(t)=v_{a s}(t)\left(\cos 0^{\circ}+j \sin 0^{\circ}\right)+v_{b s}(t)\left(\cos 120^{\circ}+j \sin 120^{\circ}\right)+v_{c s}(t)\left(\cos 120^{\circ}-j \sin 120^{\circ}\right)
$$

In computation of the electric voltage, a complex plane of voltage vector is written as follows,

$$
v_{s}=v_{\alpha s}+j v_{\beta s}
$$

(9) can be rewritten in terms of voltage as (10) and (11).

$$
\begin{aligned}
& v_{\alpha s}=v_{a s}(t)\left(\cos 0^{\circ}\right)+v_{b s}(t)\left(\cos 120^{\circ}\right)+v_{c s}(t)\left(\cos -120^{\circ}\right) \\
& v_{\beta s}=v_{a s}(t)\left(\sin 0^{\circ}\right)+v_{b s}(t)\left(\sin 120^{\circ}\right)+v_{c s}(t)\left(\sin -120^{\circ}\right)
\end{aligned}
$$

Additionally, (11) and (12) can be written as the matrix form as

$$
\left[\begin{array}{l}
v_{\alpha s}(t) \\
v_{\beta s}(t)
\end{array}\right]=\sqrt{\frac{2}{3}}\left[\begin{array}{rrr}
1 & -\frac{1}{2} & -\frac{1}{2} \\
0 & \frac{\sqrt{3}}{2} & -\frac{\sqrt{3}}{2}
\end{array}\right]\left[\begin{array}{l}
v_{a s}(t) \\
v_{b s}(t) \\
v_{c s}(t)
\end{array}\right]
$$

(13) can be analyzed in the three-phase currents transformed to the two-phase current in the complex plane with $x$ representing real part and $y$ representing imaginary part. The voltage vector in Figure 1 rotates with angular velocity around the origin in a counterclockwise direction while the axis are stationary. The transformation equation is shown in (9). The constant is multiplied to (9) to equalize the input of electricity of three and two-phases. Similarly, Clarke's transformation theory applied to transform three-phase alternating current $a, b$ and $c$ to two-phases alternating current in a stationary reference frame $\alpha-\beta$ of $d$ - $q$ system as shown in (13).

$$
\left[\begin{array}{l}
i_{\alpha}^{*} \\
i_{\beta}^{*}
\end{array}\right]=\frac{1}{v_{\alpha}^{2}+v_{\beta}^{2}}\left[\begin{array}{cc}
v_{\alpha} & v_{\beta} \\
v_{\beta} & -v_{\alpha}
\end{array}\right]\left[\begin{array}{l}
P_{c} \\
Q_{c}
\end{array}\right]
$$

The reference currents, $i_{\alpha}^{*}, i_{\beta}^{*}$ obtain from the multiplication of the voltage in a stationary reference frame $\alpha$ - $\beta$. The complex variable of electric power is $P+j Q$. The current in a stationary reference frame is $\alpha^{*}-\beta^{*}$. In applying the inverse of Clarke transformation, the reference currents, $i_{a}^{*}, i_{b}^{*}, i_{c}^{*}$ in the reference frame of sequence phase electrical system $a, b$ and $c$ have shown as in (14).

$$
\left[\begin{array}{l}
i_{a}^{*} \\
i_{b}^{*} \\
i_{c}^{*}
\end{array}\right]=\sqrt{\frac{2}{3}}\left[\begin{array}{cc}
1 & 0 \\
-\frac{1}{2} & \frac{\sqrt{3}}{2} \\
-\frac{1}{2} & -\frac{\sqrt{3}}{2}
\end{array}\right]\left[\begin{array}{l}
i_{\alpha}^{*} \\
i_{\beta}^{*}
\end{array}\right]
$$




\subsection{PI controller}

Control system theory is a mathematics and engineering. The control system is dynamical control system with expected output by using input the suitable variable in the system. The control system can be classified to two systems. Open-loop control system is the control system with its output independently controlled input. On being the closed loop control system or feedback control system, the control system with its output depended on system's input. Moreover, the control system can be classified by the characteristics of the conventional system and modern control system. The conventional control system uses the PI controller simulated in a mathematical model of the differential equation by using transformation of time domain of differential equation to frequency domain. The block diagram is simulated for analysis of system stability and designed for controlling gain value. On the contrary, the modern control system also simulates from a mathematical model with a differential equation. Then, the differential equation is transformed into the state space model without transformation of time domain to frequency domain. The rules for controlling system are designed such as pole placement [20].

In this research, the design and application of the PI controller to control the voltage between grid system. However, the PI controller is widely used in many industries. The PI controller is a control system with integral type of proportion for reducing overshoot and the noise of the system. (15) shows the control system with proportional $(P)$ and integral $(I)$ as the output of a system which directly varies with error signal [21].

$$
P=K_{P} \cdot e(t)
$$

Where $K_{P}$ is a constant proportion, $e(t)$ is the control error. The integral controller in (16) is the characteristic of the output signal from the integration signal of error.

$$
I=\frac{K_{p}}{T_{i}} \int_{0}^{t} e(t) d t
$$

Where $T_{i}$ is an integral time, the PI controllers in the time domain is a combination of (15) and (16) as shown in (17).

$$
u(t)=K_{P} \cdot e(t)+\frac{K_{P}}{T_{i}} \int_{0}^{t} e(t) d t
$$

\section{CONTROL TUNNING METHOD}

A method for designing the traditional feedback control system is pole placement method control theory.

\subsection{Pole placement}

The pole placement is the traditional method for assigning the controlling gain ratio and determining pole in the complex plane. The equation for the optimal gain value is written as [22].

$$
G_{p}(s)=\frac{1}{1+T s}
$$

$G_{c}(s)$ is PI controller for the first-order model given as,

$$
G_{c}(s)=K_{P}+\frac{K_{P}}{T_{i} s}
$$

Be sure that the symbols used in your equation have been defined before the equation appears or immediately following.

\subsection{Artificial tuning method}

At present, intelligent control system has been proposed for tuning by the artificial data processing and machine learning. Especially, the metheuristic method is the one of the artificial intelligence [23]. The metheuristic method becomes the effective tool for simulation and optimization of the parameters based on bio-inspired concept from the behavior of the animal, adopted to design the algorithm of the metheuristic method which is the modern optimization. The examples of metheuristic method are particle swarm optimization (PSO), gravitational search algorithm (GSA), neural networks combined with particle swarm optimization, and neural networks combined with a gravitational search algorithm.

\subsection{Particle swarm optimization}

Particle swarm optimization is an algorithm for optimization which imitates the group animal movement and their behaviors such as bird and fish. The scientist found that the behavior of the flock of bird is usually acted as follows.

a. Each bird will fly out if it is too near to another bird. 
b. Each bird will fly in the same direction of the flock direction.

c. Each bird will try to keep the distance to each other equally.

Particle swarm optimization is developed by Kennedy and Eberhart [24]. It imitates the behavior of animal movement or a flock of immigration bird randomly. The movement of animal such as fish and bird can be classified into two types, the synchronous movement of elements and diverted and the re-conglomerated movement. This is called a particle movement. The particle movement behaves the social behavior by using the responded parameters such as the number of bird or particle. The behavior designs for finding the direction of group of bird or particle. Then, the all bird or particle in the group will move to the optimal direction, including correct position and its velocity. This behavior is repeated until reaching the objective.

Let $d$ be a searching space and the $i^{\text {th }}$ particle representing $X_{i}=\left(\mathrm{x}_{i 1}, \mathrm{x}_{i 2}, \ldots, \mathrm{x}_{i d}\right)$. Let $V$ be the velocity vector of particles, namely $V_{i}=\left(v_{i 1}, v_{i 2}, \ldots . ., v_{i d}\right)$. Let the previously optimal solution be $P_{i}=\left(p_{i 1}, p_{i 2}, \ldots . ., p_{i d}\right)$. If the $g^{\text {th }}$ is the optimal solution for the current searching, the flock of the particle will be adjusted by (20) and (21), where $w$ is inertia weight, $c_{1}$ and $c_{2}$ are the acceleration factors $r_{1}$ and $r_{2}$ are uniform random variables in $(0,1) .(22)$ is represented by weight function $(w)$.

$$
\begin{aligned}
& v_{i d}^{n+1}=w v_{i d}^{n}+c_{1} r_{1}^{n}\left(\mathrm{p}_{i d}^{n}-\mathrm{x}_{i d}^{n}\right)+\mathrm{c}_{2} r_{2}^{n}\left(\mathrm{p}_{g d}^{n}-\mathrm{x}_{i d}^{n}\right) \\
& x_{i d}^{n+1}=x_{i d}^{n}+v_{i d}^{n+1} \\
& w_{1}=w_{\max }-\left(\frac{w_{\max }-w_{\min }}{k_{\max }}\right) k
\end{aligned}
$$

The particle swarm methods are summarized as the following states.

State 1: Configure the search parameters $(k)$, initial search cycle $(k=0)$, and maximum search cycle $\left(k_{\max }\right)$ particle $(v)$

State 2: Random the initial particle together with initial position and initial speed of each internal

State 3: Calculate the objective function value $(J)$ of an initial particle is to be a default answer of $P_{\text {best. }}$

State 4: Calculate the objective function value of each particle, which the minimum objective function value $\left(J_{1}\right)$ is to be determined an answer of $P_{\text {best }}$.

State 5: If $J_{1}<J$, adjust $P_{\text {best }}=P_{\text {best }}$

State 6: Select the particles given the least $P_{\text {best }}$ the value of all to adjust $P_{\text {best }}=P_{\text {best }}$.

State 7: Adjust the speed and position of each particle by using (21) and (22), respectively.

State 8: If $k \geq k_{\max }$, terminate the searching process, otherwise adjust $k=k+1$ and loop back to stage two to continue the searching process in the next iteration.

\subsection{Gravitational search algorithm}

The gravitational search algorithm is the optimal method using the gravitational law with the knowledge of Newton's second law. Namely, the acceleration depends on the force on the object and the mass of that object as shown in (23).

$$
a=\frac{F}{m}
$$

Where the $F$ is force and $m$ is the acceleration a (via mass). The gravitational search algorithm is assembled of an agent of an answer set. This can interact with other agents. Each agent has a different mass. In a process of time, each agent is attracted to each other caused the system which is moving away. Agent masses are $N$ defined as

$$
A_{i}=\left(a_{i}^{1}, a_{i}^{2}, \ldots, a_{i}^{d}\right)
$$

Where $A_{i}$ is an agent system, $i$ is a value of agent's position; $i=1,2, \ldots, N$ and $d$ is a dimension of agents, $d$ $=1,2, \ldots, D$ in a grave state. Thus, an object with a force at any time can be obtained from the relation between $M_{a i}(t)$ forcing on an agent $j$ and $M_{a j}(t)$ with an agent stress $i$ and difference between agents $a_{i}^{d}(t)$ and $a_{j}^{d}(t)$ , $G(t)$ is a gravitational constant, $R_{i j}(t)$ is the Euclidean distance between the agents and $\varepsilon$ is the constants. The gravitational force can expressed as (25)

$$
F_{i j}^{d}(t)=G(t) \frac{M_{a i}(t) M_{a j}(t)}{R_{i j}(t)+\varepsilon}\left(a_{j}^{d}(t)-a_{j}^{d}(t)\right)
$$


Where $R_{i j}(t)=\left\|A_{i}, A_{j}\right\|_{2}$ and $G(t)=G_{0} e^{-\alpha \frac{t}{T}}, G_{0}$ is an initial Euclidean distance, $T$ is the number of loops and $\alpha$ is the total gravitational constant of the agent. Thus, $i$ is a random of agent's gravity at a position $j$ in a range $[0,1]$.

$$
F_{i}^{d}(t)=\sum_{j=1, j \neq 1}^{N} \operatorname{ran}_{j} F_{i j}^{d}(t)
$$

From the Newton's second law has mentioned that the acceleration of an agent of the motion law as expressed as

$$
a_{i}^{d}(t)=\frac{F_{i}^{d}(t)}{M_{i}(t)}
$$

Where $M_{i}(t)$ is an initial value the agent $i$ in the gravitational search algorithm determined that,

$$
M_{a i}=M_{p i}=M_{i i}=M_{i},(i=1,2,3, \ldots, N)
$$

Where $M_{i i}(t)$ is an initial value of agent $i$ in each round of the agent's mass adjustment can be adjusted the mass value by (29).

$$
M_{i}(t)=\frac{\operatorname{fit}_{i}(t)-\operatorname{worst}(t)}{\operatorname{best}(t)-\operatorname{worst}(t)}
$$

$f_{i t}(t)$ is an agent's appropriate value or the objective function value and $M_{i}(t)$ is determined by (30).

$$
M_{i}(t)=\frac{m_{i}(t)}{\sum_{J=1}^{N} m_{j}(t)}
$$

The objective function of the maximum and minimum problems can be written as the following equations.

$$
\begin{aligned}
\operatorname{best}(t) & =\min _{j \in\{1, \ldots N\}} f i t_{j}(t) \\
\text { worst } & =\operatorname{mix}_{j \in\{1, \ldots N\}} f i t_{j}(t)
\end{aligned}
$$

The velocity and position of the agent steps are adjusted by the Newton's motion rules as (32) and (33), respectively.

$$
\begin{aligned}
& v_{i}^{d}(t+1)=\operatorname{rand} \times v_{i}^{d}(t)+a_{i}^{d}(t) \\
& x_{i}^{d}(t+1)=x_{i}^{d}(t)+v_{i}^{d}(t+1)
\end{aligned}
$$

Where rand is a random value from the range of [0,1], and $v_{i}^{d}(t)$ is a speed value, an agent position, $x_{i}^{d}(t)$ dimension $d$ at any time of $t$.

\subsection{Artificial neural network}

The artificial neural network is actually based on the human brain. There are two nerve cells in the human's brain, which are for calculation and transmitting of the calculated value results to other nerves immediately using the electrical concept. The neuron network method is represented in the human's brain. The main components of the neural network are nerve cells, which the nerve cell groups that are recognized. Actually, humans are complicated in the process of recurring [25]. However, there are still four compositions for natural nerve cells. These called by biological name that are dendrites, soma, axon, and synapses. There are many architectures feed forward, neuron network is widely used architectures to solve a nonlinear problem.

Figure 2 shows the feed forward neural network architecture. It consists of the input, hidden and output layers. The relationships between input layer and hidden layer can be calculated the sum of input variable values and the weight values that connected to the hidden layer. Then, the total inputs can be calculated by multiplying the data, with weight and bias as (35).

$$
n_{j}^{1}=\sum_{j=1}^{M} x_{i} w_{i j}^{1}+b_{j}^{1}, i=1, \ldots, N
$$

Where $x_{i}$ is the input data feed to node $i, w_{i j}$ is the weight value between feeder layers and hidden layer, $b_{j}^{l}$ is data dependency. Actually, $i$ variable is the number of nodes in the input layer to be equal of 1 to $N$, and $j$ is equal 1 to $M$ nodes. The input data value that moves out from the hidden layer to output layer is calculated by (36).

$$
y_{j}^{1}=f^{1}\left(n_{j}^{1}\right)
$$


Where $f^{1}$ is transfer function between input and hidden layers. Between the hidden and output layers, the total input data can be calculated by the multiplication of the weight and bias values as (37).

$$
n_{k}^{2}=\sum_{k=1}^{Q} y_{j}^{1} w_{j k}^{2}+b_{k}^{2} \quad, j=1, \ldots, M
$$

Where $y_{j}^{l}$ is the input data feed to node $j, w_{j k}^{2}$ is the weight value between hidden layer and output layer, $b_{k}^{2}$ is biased, $j$ is the number of nodes in the hidden layer, which is equal 1 to $M$, and $j$ is equal 1 to $Q$. The input data node moved out from the hidden layer to the output layer, which can be calculated by (38).

$$
y_{k}^{2}=f^{2}\left(n_{k}^{2}\right)
$$

Where $f^{2}$ is transfer function between the hidden layer and output layer. (36) to (39) can be calculated the output layer as shown in (39).

$$
y_{k}^{2}=f^{2}\left(\sum_{k=1}^{Q} f^{1}\left(\sum_{j=1}^{M} x_{i} w_{i j}^{1}+b_{j}^{1}\right) w_{j k}^{2}+b_{j}^{2}\right)
$$

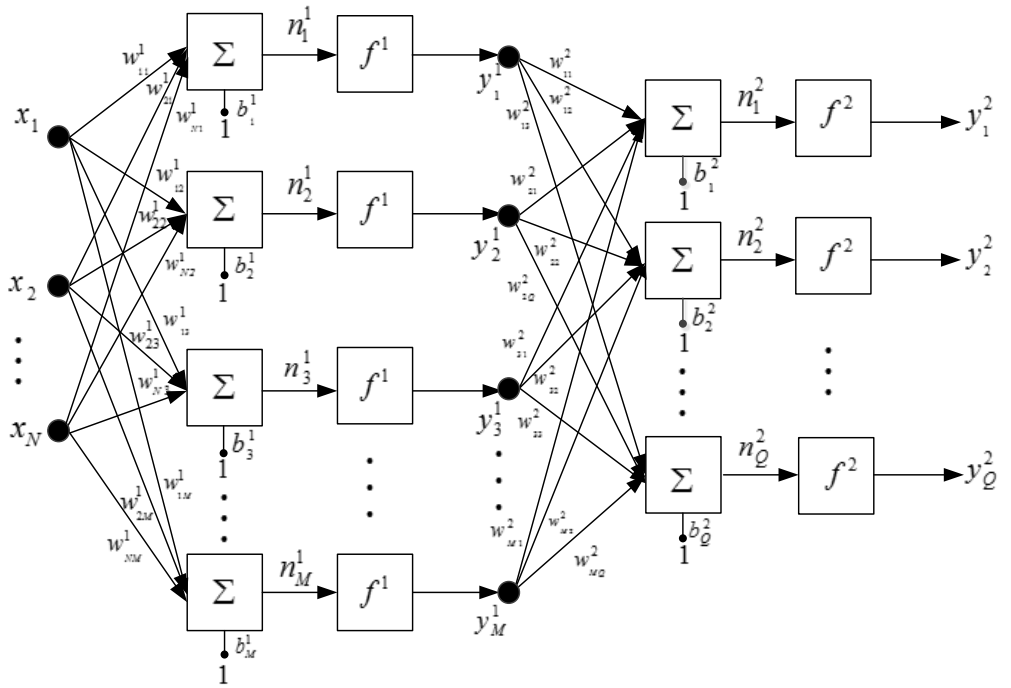

Figure 2. The architecture of ANN [26]

\subsection{Hybrid metaheuristic optimizations}

In this research, the weights of ANN are optimized by using PSO and GSA to find the optimal gains, $K_{p}, K_{i}$ for PI controllers. Figure 3 shows the steps of the hybrid methods, combination of ANN and metaheuristic optimizations.

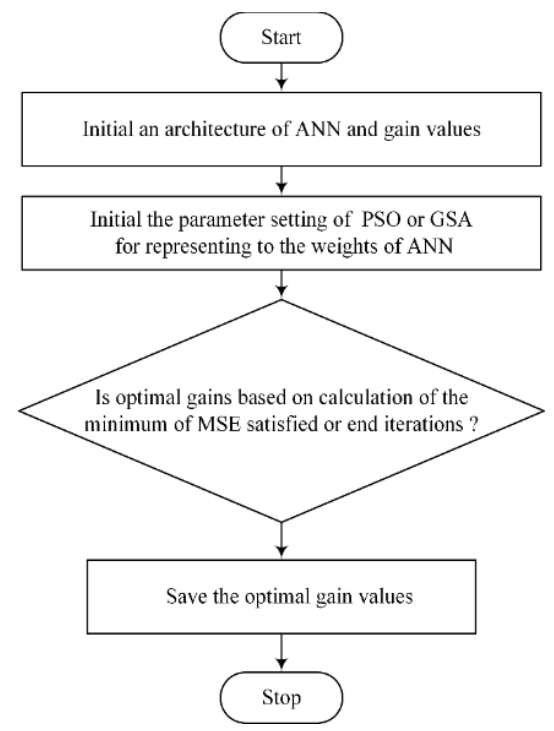

Figure 3. Steps of hybrid methods for finding optimal gains 
In Figure 3, the steps of hybrid method can be explained as follows:

Step 1. The architecture of ANN and the initial gain values are defined.

Step 2. The weights are initiated at random and also the parameters of PSO and GSA are setup.

Step 3. If the gains is not satisfied or end the iteration. The weights are updated by PSO or GSA and iteration are counted. Otherwise, the optimal gains are saved.

In the measurement performance of ANN process, the mean square error (MSE) has been calculated as [27].

$$
M S E=\frac{1}{N} \sum_{i=1}^{N}\left(y_{i}-t_{i}\right)^{2}
$$

Where $N$ is amount of target data, and the observed data is determined by $t=\left[t_{1} t_{2} t_{3} \ldots t_{N}\right]^{T}$

\section{EXPERIMENT SETTING}

Figure 4 demonstrates the testing of power flow control system, which consists of actual power and reactive power based on a grid system on dSPACE-DS1104 model with MATLAB/Simulink. The experimental setup has tested the power control system at the stepping of 0-100 w, 0-200 w, 0-300 w and 0$400 \mathrm{w}$ without load. The comparison of power reaction regulating by the PI controller, which the gains of PI controller are tuned by PSO and GSA, neural networks with particle swarm optimization (PSO-ANN) and neural networks with a gravitational search algorithm (GSA-ANN).

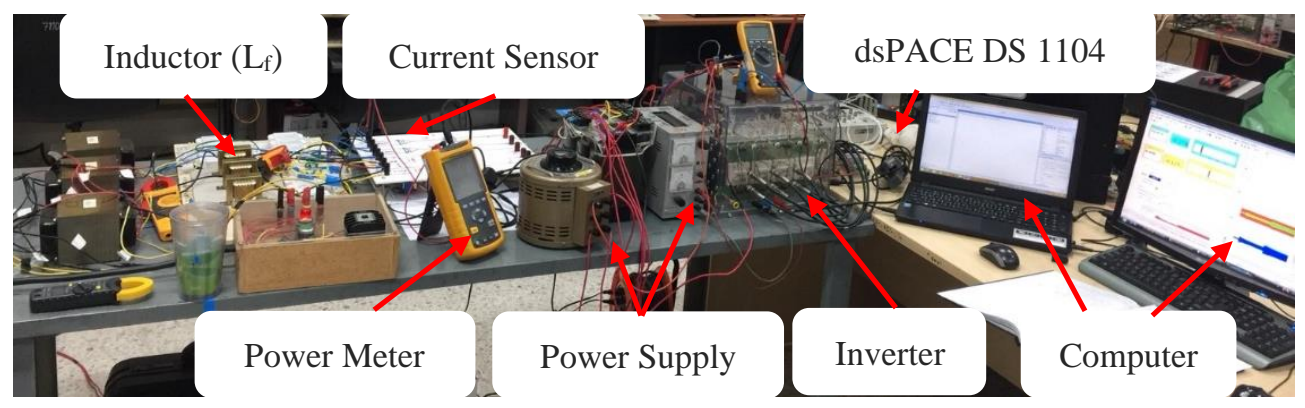

Figure 4. The power flow control system

Figure 5 presents the experimental setup in the laboratory room, which the main components contained on dSPACE-DS1104 DSP controller board, induction motor, PMSG and three-phase power supply. The three-phase power supply is rectified to maintain the constant voltage before transferring to the provincial electricity authority system. The block diagram of the proposed system is simulated by MATLAB/Simulink programs. It is normally not complicated to control and design in simulink the dSPACE-DS1104 DSP board.

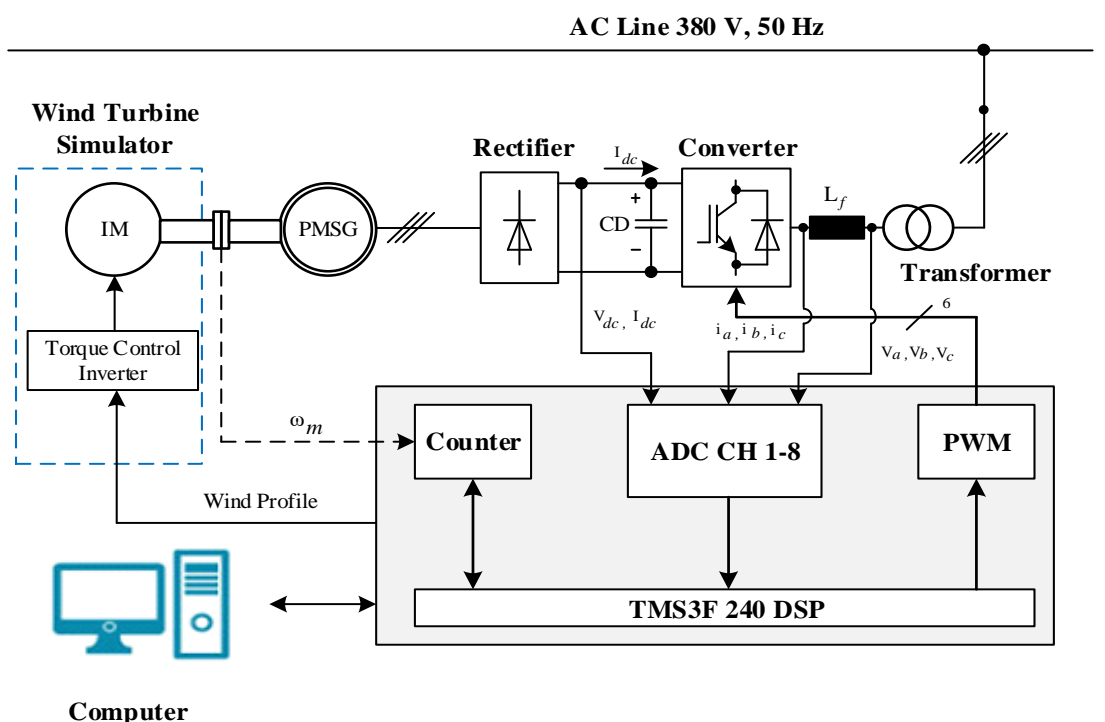

Figure 5. Experimental setup 
Figure 6 demonstrates the design system by the MATLAB/Simulink based on dSPACE-DS1104 DSP board. The dSPACE-DS1104 DSP board is accessed through the program control desk developer to analyze and evaluate the efficiency of the power control system.

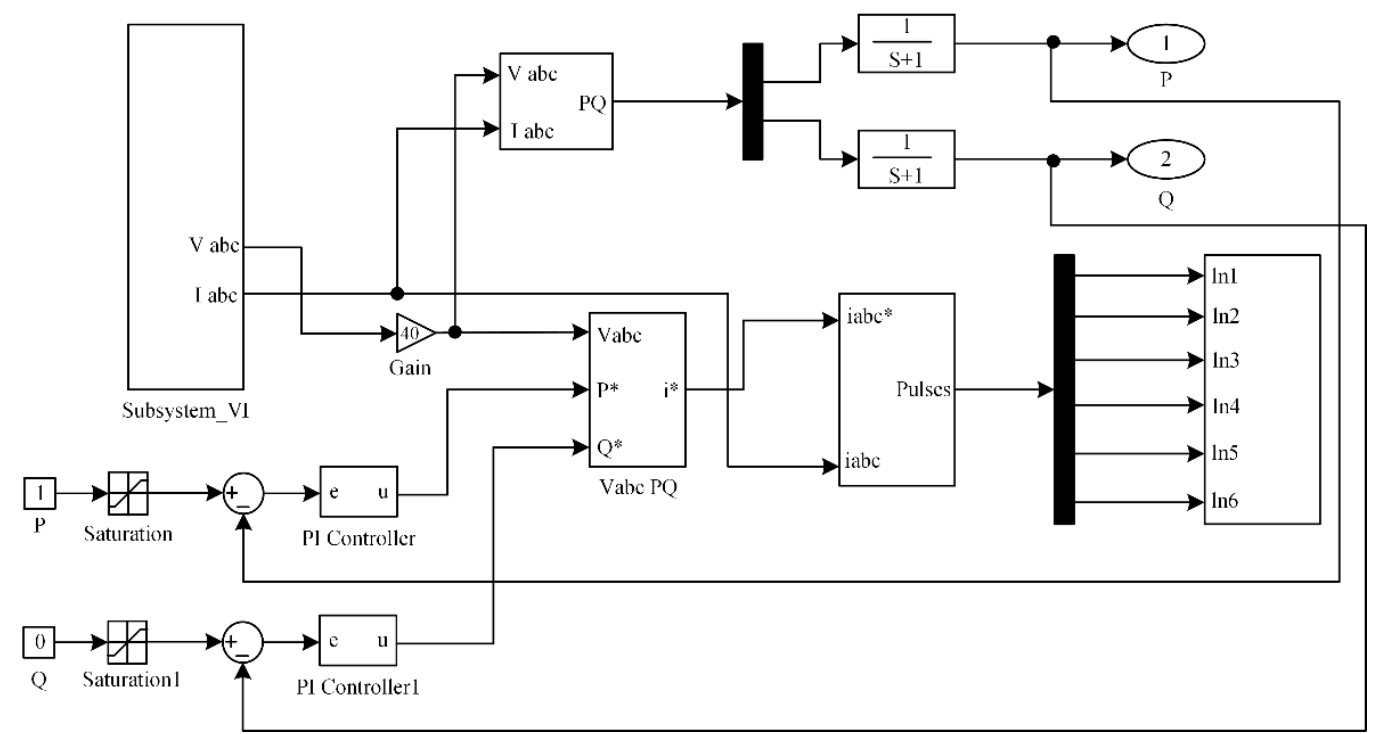

Figure 6. Simulink diagram

\section{RESULTS AND DISCUSSION}

The architecture of ANN for the experimental design has three layers, two nodes in the input layer, fifteen nodes in the hidden layer and a node in the output layer. For updating the weights for tuning the gains of PI controller, the initial parameter values for PSO and GSA as shown in Table 1. Moreover, Table 2 shows the parameter settings of a power grid for the proposed system.

Table 1. Parameter settings of PSO and GSA

\begin{tabular}{cccc}
\hline Parameter of PSO & \multicolumn{3}{c}{ Parameter of GSA } \\
\hline Number of particles & 30 & Number of masses & 30 \\
Number of iterations & 100 & Number of iterations & 100 \\
Intertie coefficient & 0.1 & Gravitational constant & 1 \\
Damping ratio of inertia coefficient & 0.99 & Position vector & Random \\
Personal acceleration coefficient & 2 & Acceleration vector & Random \\
\hline
\end{tabular}

Table 2. The parameter settings of power circuit

\begin{tabular}{cc}
\hline Parameter & Value \\
\hline dSPACE & DS1104 \\
Active power & $0-400 \mathrm{w}$ \\
Reactive power & 0 \\
Resistance & $10 \Omega$ \\
Inductor & $100 \mathrm{mH}$ \\
\hline
\end{tabular}

Table 3. The measured parameters of electrical power of system from the power meter

\begin{tabular}{ccccccccc}
\hline $\begin{array}{c}P^{*} \\
(\text { Step })\end{array}$ & $\begin{array}{c}P \\
(\mathrm{w})\end{array}$ & $\begin{array}{c}Q \\
(\mathrm{var})\end{array}$ & $\begin{array}{c}S \\
(\mathrm{VA})\end{array}$ & $\begin{array}{c}i_{\text {grid }} \\
(\mathrm{A})\end{array}$ & $\begin{array}{c}\text { THDi } \\
\%\end{array}$ & $\begin{array}{c}\text { THDV } \\
\%\end{array}$ & PF. & DPF. \\
\hline $0-100$ & 90 & 63 & 109 & 0.72 & 4.12 & 1.65 & 0.90 & 0.98 \\
$0-200$ & 190 & 73 & 203 & 2.54 & 9.20 & 1.70 & 0.97 & 0.99 \\
$0-300$ & 289 & 83 & 300 & 2.75 & 9.70 & 1.70 & 0.97 & 0.99 \\
$0-400$ & 395 & 99 & 394 & 3.60 & 9.70 & 1.70 & 0.98 & 0.99 \\
\hline
\end{tabular}

As can be seen in the Table $3, P^{*}$ is a reference power in the range $0-400 \mathrm{w} . P$ and $Q$ are an active power and a reactive power, respectively. $S$ is an apparent power, $i_{\text {grid }}$ is a grid current, THDi is the sum of harmonic currents, THDV is the sum of harmonic voltage. The pf. is a power factor and DPF. is the sum of power factor. The current flowing into the grid is $3.60 \mathrm{~A}$. In analysis result, the power factor indicated that the steps of $P^{*}$ in $0-200 \mathrm{w}$ and $0-400 \mathrm{w}$ is suitable to determine the step test in the experiment. 
Table 4. The gains of the PI controller

\begin{tabular}{cccc}
\hline No. & Method & $\mathrm{K}_{\mathrm{p}}$ & $\mathrm{K}_{\mathrm{i}}$ \\
\hline 1 & Pole Placement & 2.00 & 2.00 \\
2 & PSO & 2.20 & 3.00 \\
3 & GSA & 1.94 & 2.36 \\
4 & PSO-ANN & 2.01 & 2.11 \\
5 & GSA-ANN & 1.98 & 1.95 \\
\hline
\end{tabular}

Table 4 illustrates the gains, $K_{P}$ and $K_{i}$ by using the traditional algorithms, pole placement, and intelligent methods, PSO, GSA, PSO-ANN and GSA-ANN. It summarizes that the gain results obtained from the five tuning methods in the range 1.95 to 3.00. Accordingly, the gains from Table 4 are implemented in the proposed system by changing the step of active power reference at $200 \mathrm{w}$ to $400 \mathrm{w}$. The experimental results of the response show in Figure 7 to Figure 11.

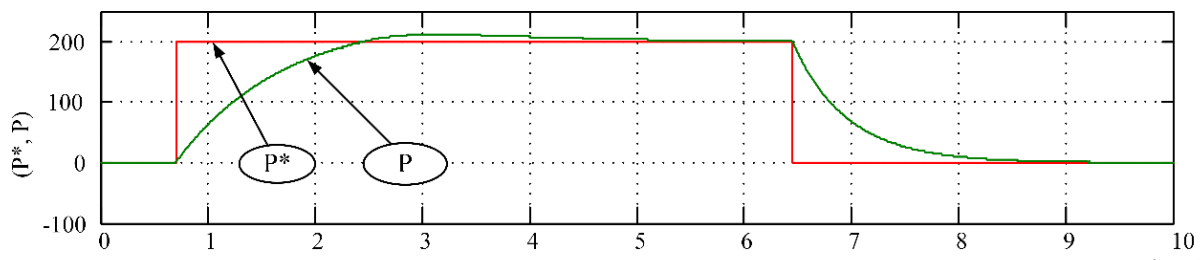

(a) Active power reference at $200 \mathrm{w}$

Time(s)
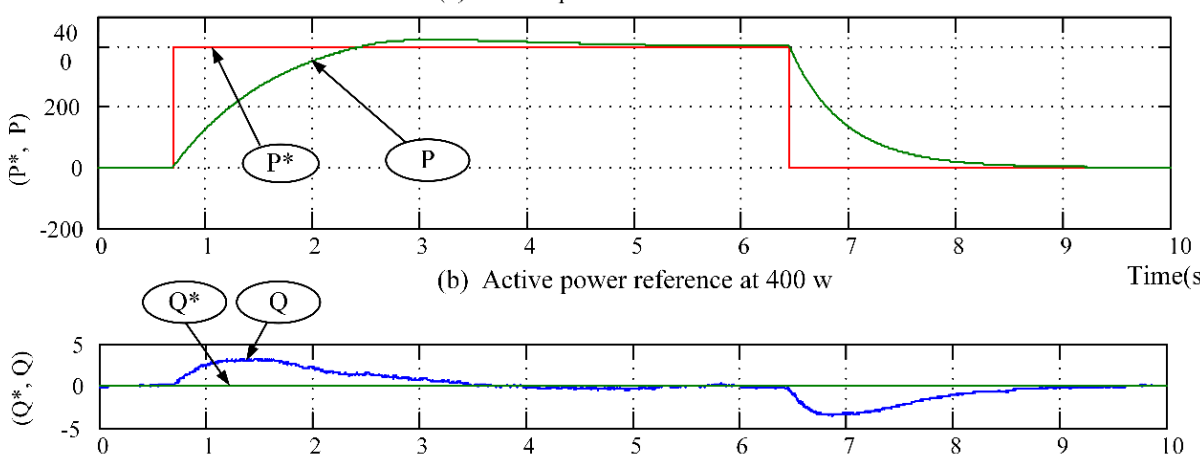

(c) The flow of reactive power Time(s)

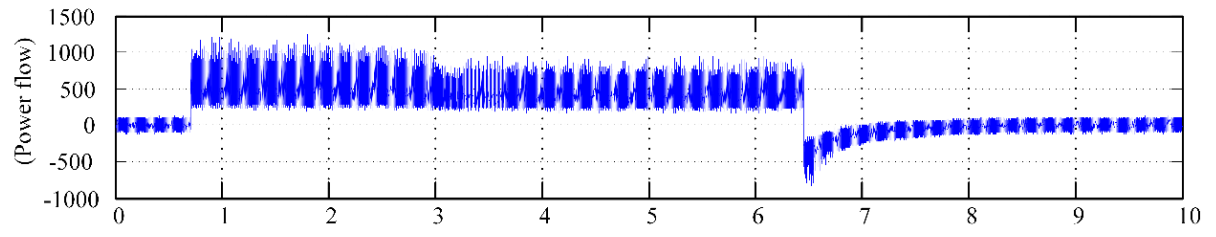

(d) Power flow Time(s)

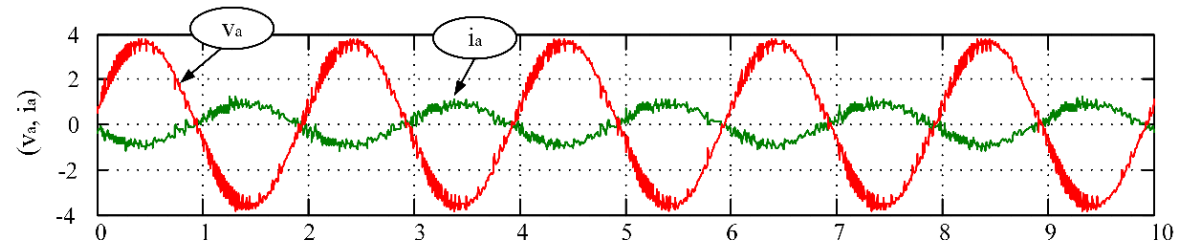

(e) The relationship between current and voltage

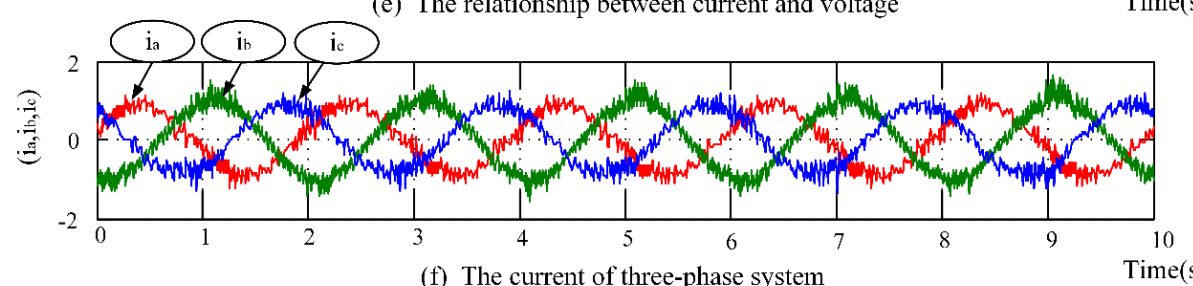

(f) The current of three-phase system

Figure 7. Step change of active power reference at $200 \mathrm{w}$ to $400 \mathrm{w}$ tuning gains by the pole placement

Figure 7(a), (b) indicates the power flow control system at $200 \mathrm{w}$ to $400 \mathrm{w}$ using pole placement controller. The red signal represents a reference power and the green signal represents the PI controller's behaviour. The obtained results found that the designed system has a little overshoot due to the green signal rises up beyond 
the red signal. By the way, the performance of this system is still unacceptable. Figure 7(c) displays the flow of reactive power, according to control system, and this design requires to be zero. Figure 7(d) indicates the flow of actual power according to the provincial electricity authority's grid system to the load, and also the flow out from the inverter mode into the grid system. Moreover, Figure 7(e) compares the relationship between the current and voltage at the steady load condition. It found that the current phase has a lagging voltage phase angle. Figure 7(f) shows the three-phase actual power system such as phase a, b and c, respectively.

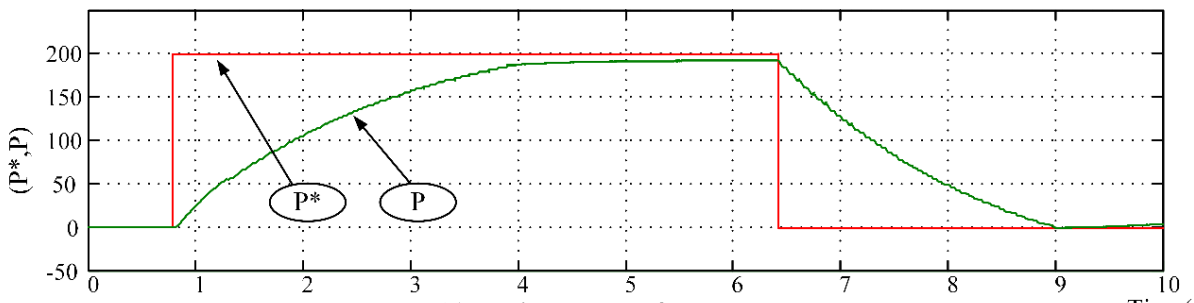

(a) Active power reference at $200 \mathrm{w}$

Time(s)
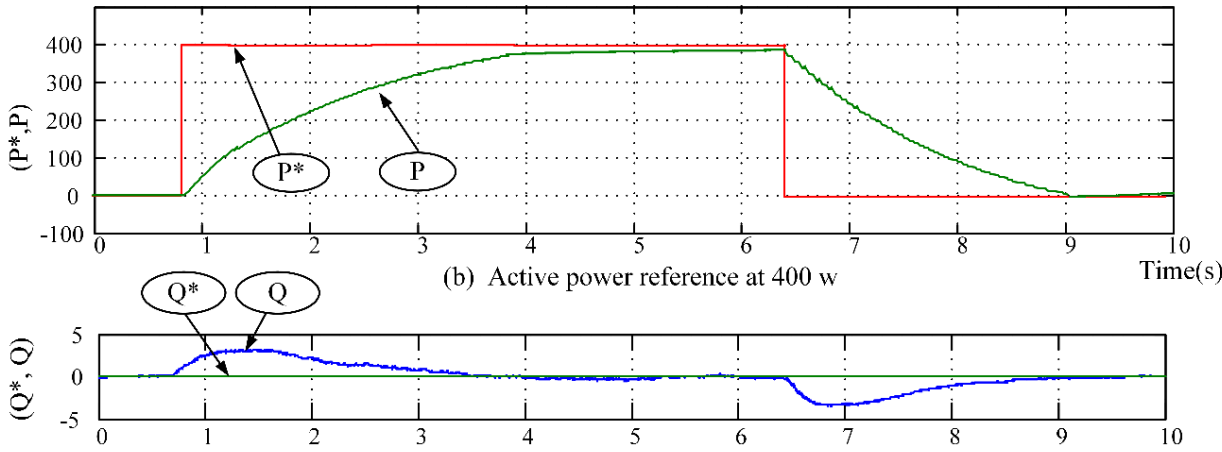

(c) The flow of reactive power

Times $(s)$

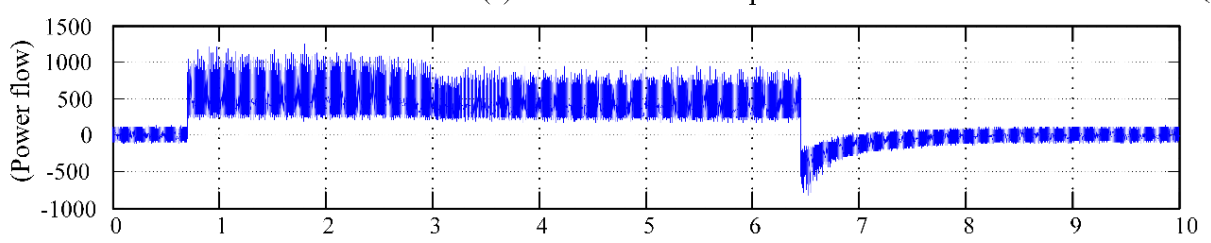

(d) Power flow

Time(s)

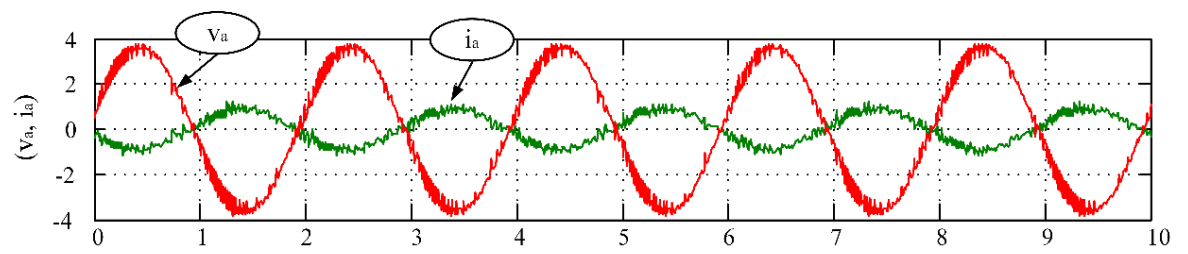

(e) The relationship between current and voltage

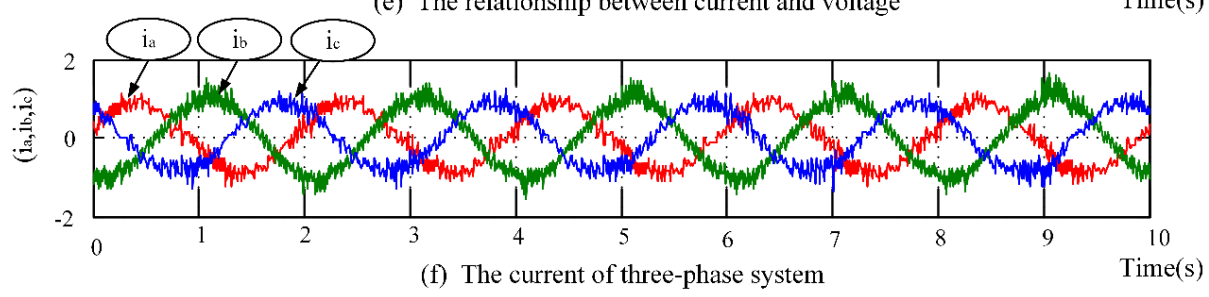

Figure 8 . Step change of active power reference at $200 \mathrm{w}$ to $400 \mathrm{w}$ tuning gains by PSO

Figure 8(a), (b) shows the flow of step change of active power reference at $200 \mathrm{w}$ to $400 \mathrm{w}$ tuning gains by PSO. The red signal is a reference power and the green signal is the PI controller's behaviour. The obtained results found that the designed system is still not stable and unacceptable due to the green signal is not climbing up the red signal. While Figure 8(c) considers the flow of the reactive power, according to the control system, required a reference value of zero. In addition, Figure 8(d) presents the flow of actual power, according to provincial electricity authority's grid system to the load. Then, it flows back again from inverter mode into the grid system. Moreover, Figure 8(e) demonstrates the relationship between current and voltage at steady load condition. It is found that the current phase angle has been just a little lagging of the voltage 
phase angle. Finally, Figure 8(f) combines the actual electrical current of three-phase system which are phase $\mathrm{a}, \mathrm{b}$, and c.

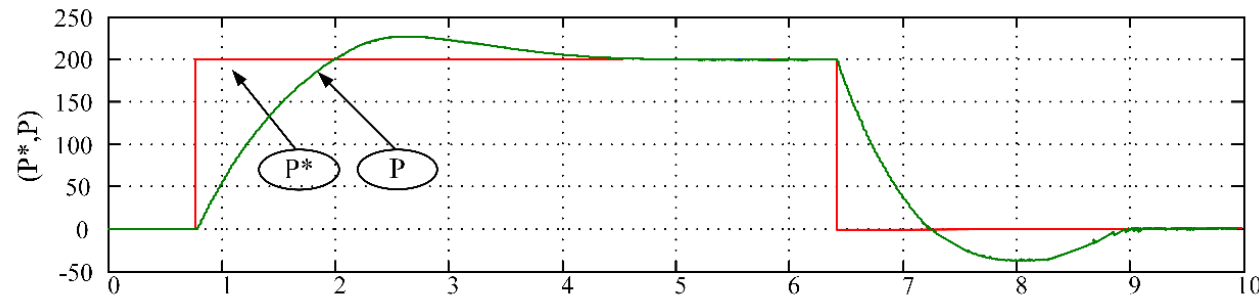

(a) Active power reference at $200 \mathrm{w}$ Time(s)
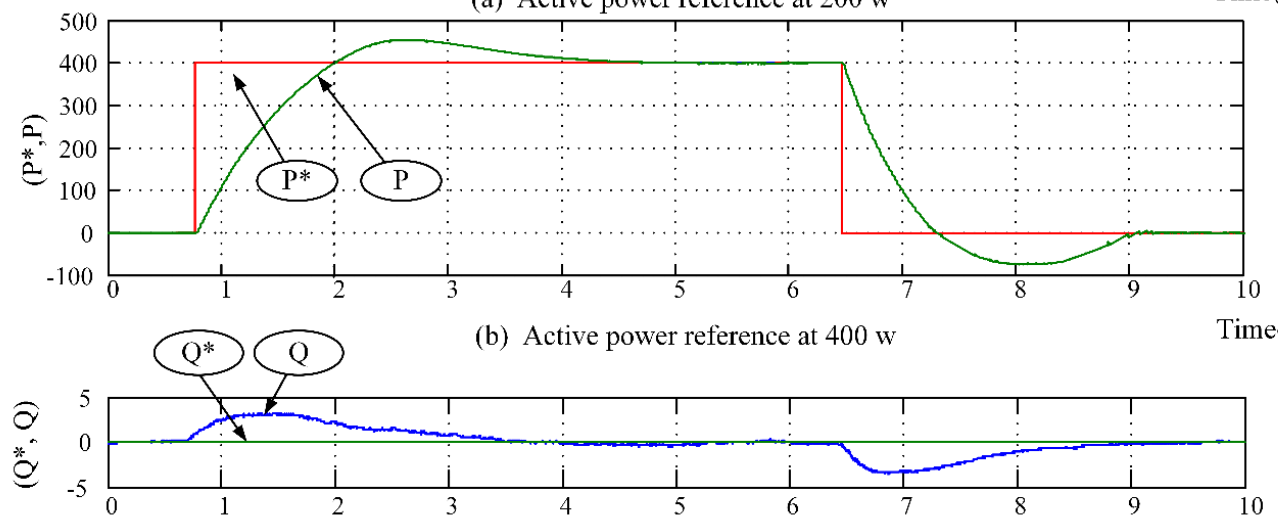

(c) The flow of reactive power Time(s)

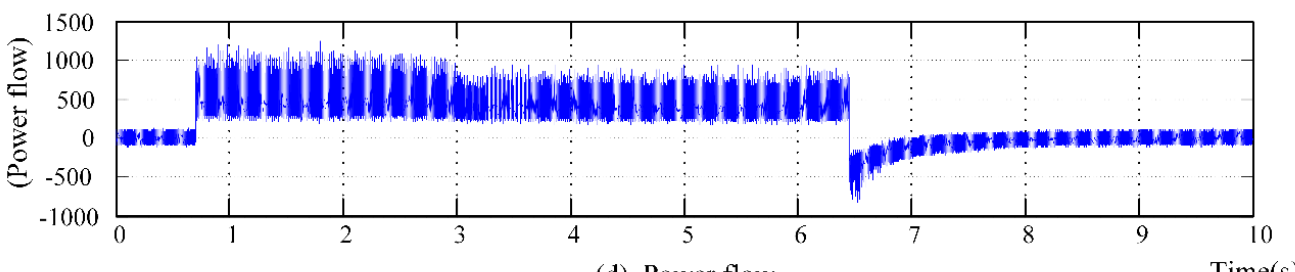

(d) Power flow

Time(s)

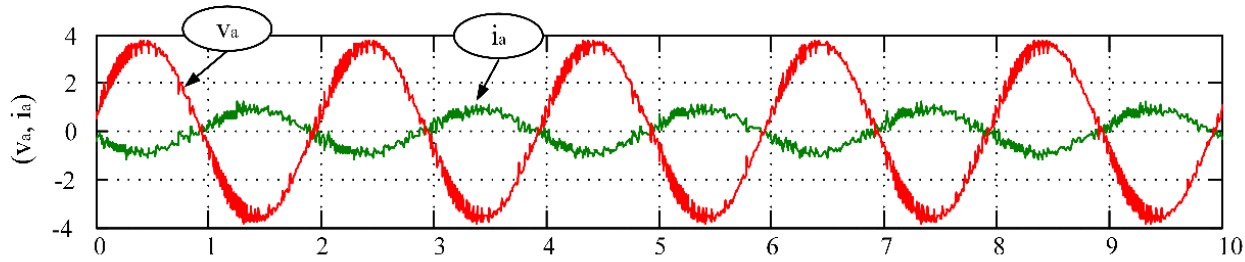

(e) The relationship between current and voltage

Time(s)

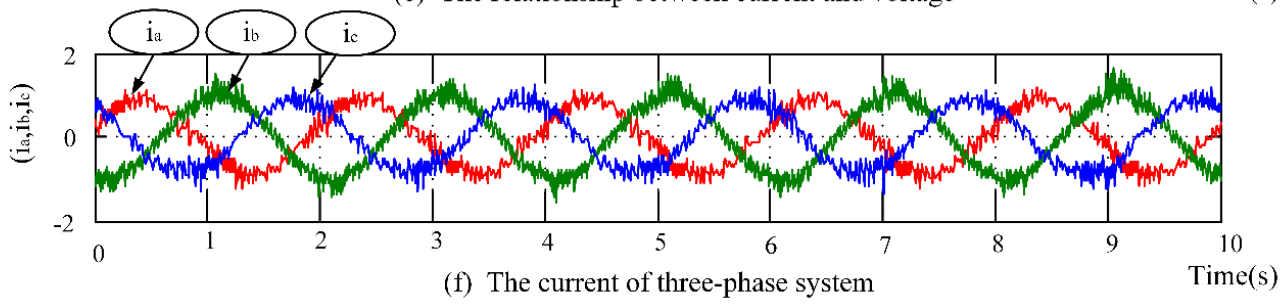

Figure 9. Step change of active power reference at $200 \mathrm{w}$ to $400 \mathrm{w}$ tuning gains by GSA

Figure 9(a), (b) displays the flow of step change of active power reference at $200 \mathrm{w}$ to $400 \mathrm{w}$ tuning gains by GSA. The red signal is a reference power and green signal is the PI controller's behaviour. The obtained results show that the flow of the power control system has an overshoot condition because the green signal in which controls PI controller goes up beyond the red signal obviously. Thereupon, this result is still unacceptable in the real application. On the other hand, Figure 9(c) presents the flow of reactive power, according to the control system, required to be zero. In addition, Figure 9(d) evinces the flow of actual power, according to the provincial electricity authority's grid system out to the load and again flows out from the inverter mode into the grid system. Moreover, Figure 9(e) displays the current and voltage signals at the steady load situation. Their current phase angle has been just a little lagging of the voltage phase angle. Finally, in Figure 9(f) concludes the actual electrical current of three-phase system such as phase a, b, and c. 


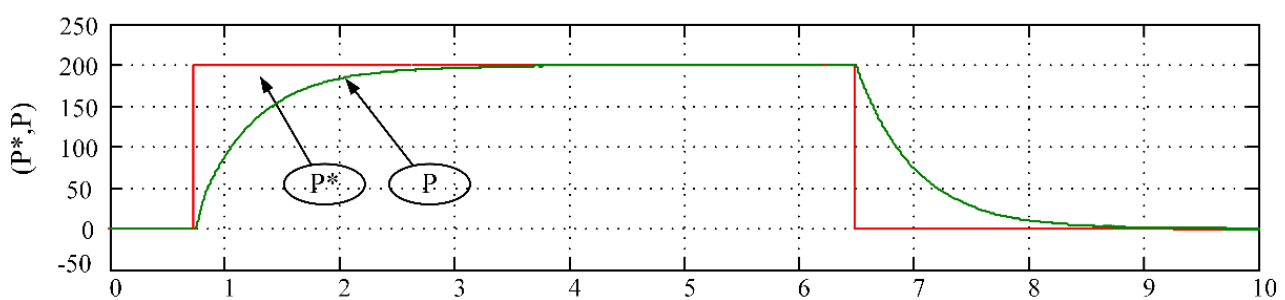

(a) Active power reference at $200 \mathrm{w}$

Time(s)

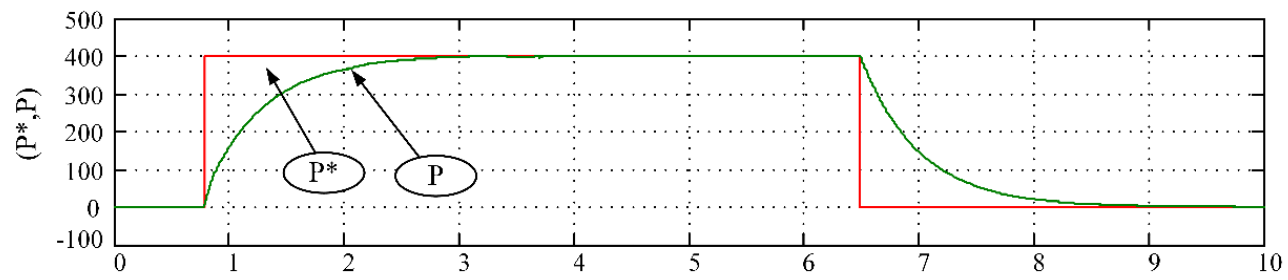

(b) Active power reference at $400 \mathrm{w}$

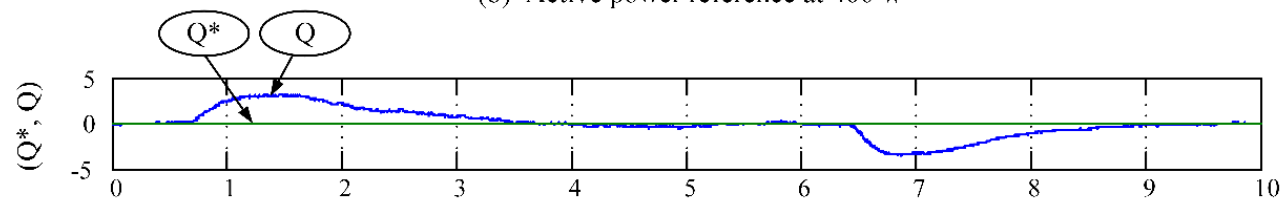

(c) The flow of reactive power

Time(s)

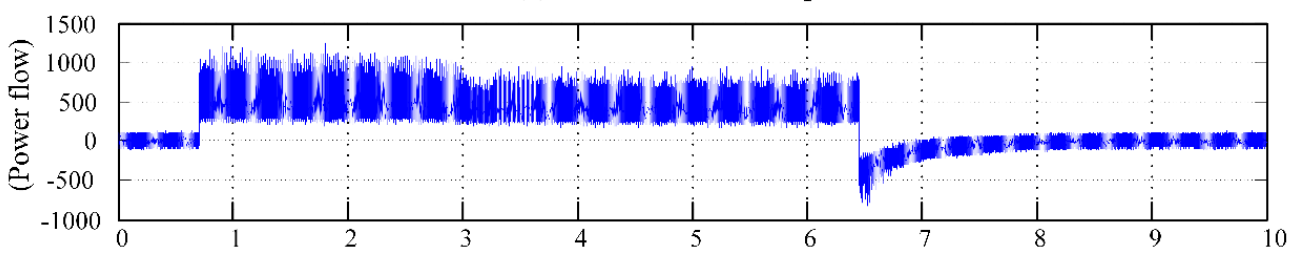

(d) Power flow

Time(s)

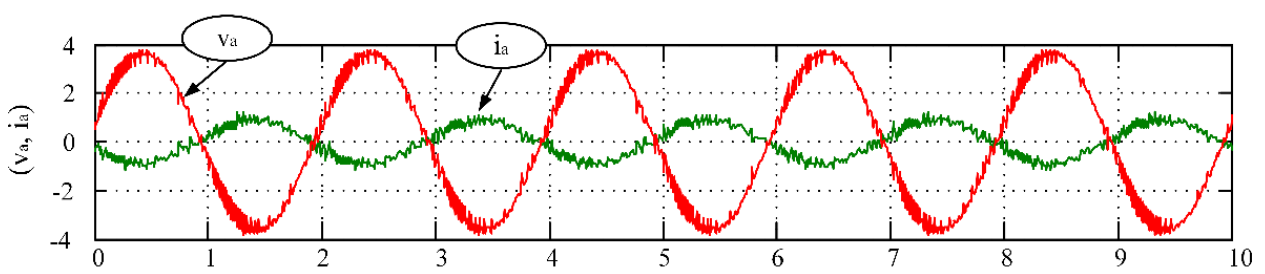

(e) The relationship between current and voltage

Time(s)

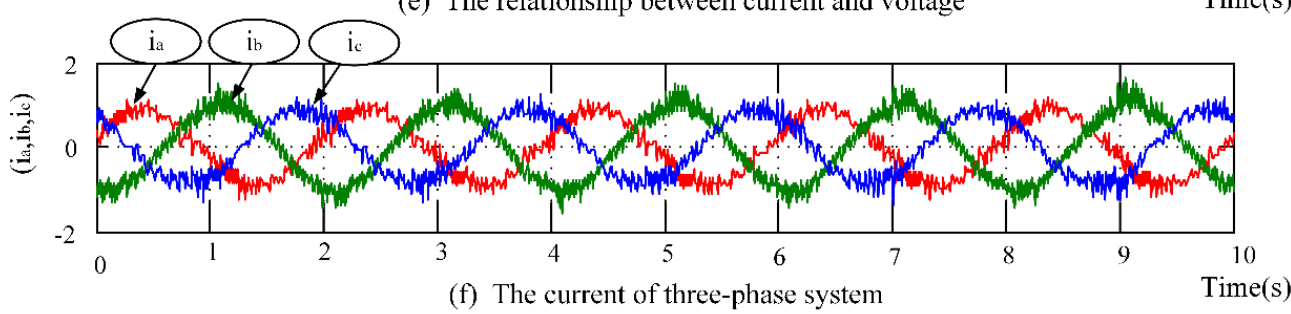

Figure 10. Step change of active power reference at $200 \mathrm{w}$ to $400 \mathrm{w}$ tuning gains by PSO-ANN

Figure 10(a), (b) shows the step change of active power reference at $200 \mathrm{w}$ to $400 \mathrm{w}$ tuning gains by PSO-ANN. The obtained results found that the red signal is a reference power and the green signal is the behaviour of PI controller. It found that there is no overshoot exiting in the testing. Namely, green signal controlled PI controller is risen up according to the reference signal. This considered design system is an acceptable result due to the grain value obtained, optimal control condition and stability of system as well. However, Figure 10(c) presents the flow of reactive power, according to control system, which requires a value of zero. In the Figure 10(d) appears the flow of actual power, according to the control system from provincial electricity authority's grid system into the load and also flows out from the inverter mode into the grid system. Furthermore, Figure 10(e) compares the current and voltage phase angle at the stable load. It is found that the current phase angle has a slightly lagging of the voltage phase angle. Finally, Figure 10(f) presents the actual power of the three-phase power system, phase $a, b$ and $c$. 


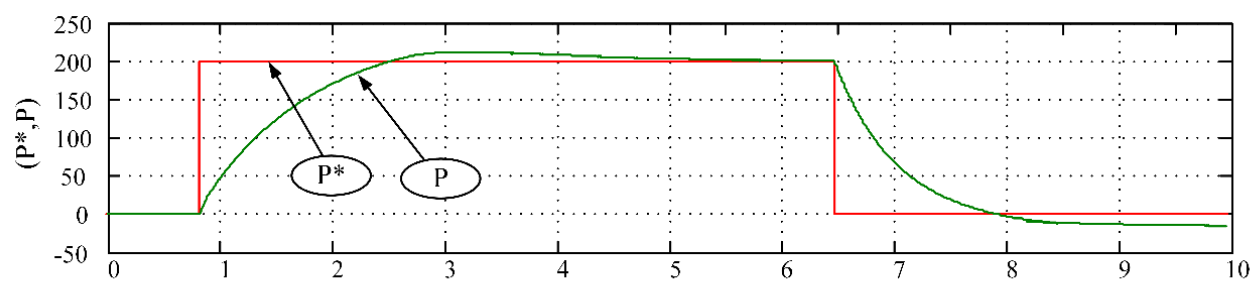

(a) Active power reference at $200 \mathrm{w}$

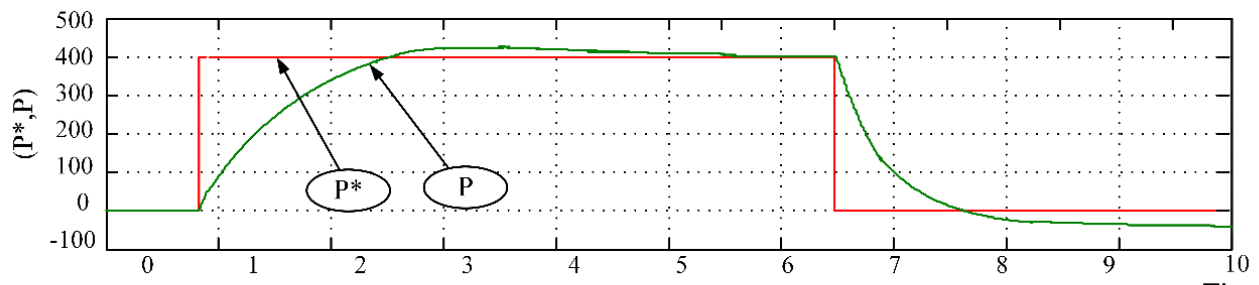

(b) Active power reference at $400 \mathrm{w}$

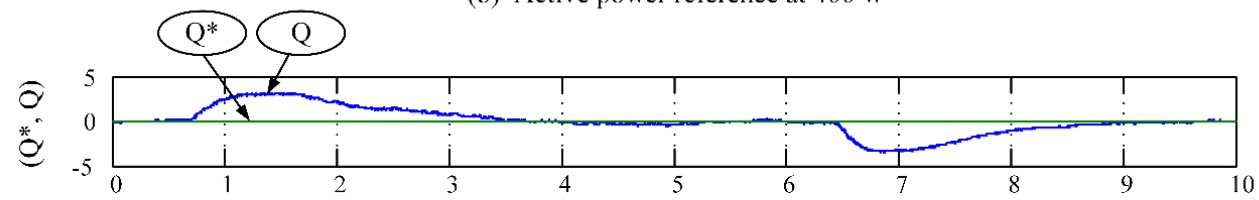

(c) The flow of reactive power

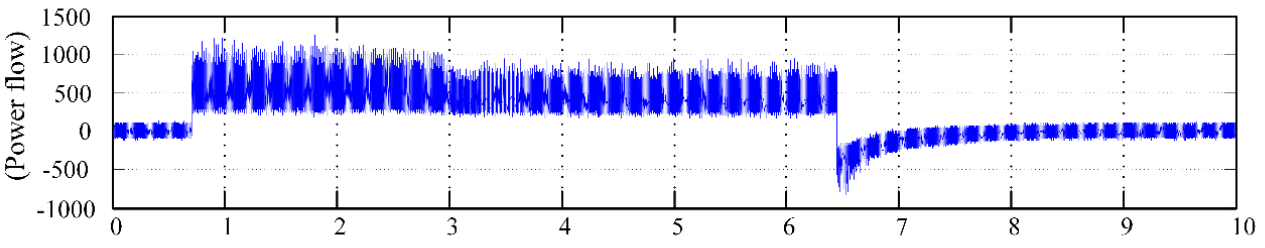

(d) Power flow

Time(s)

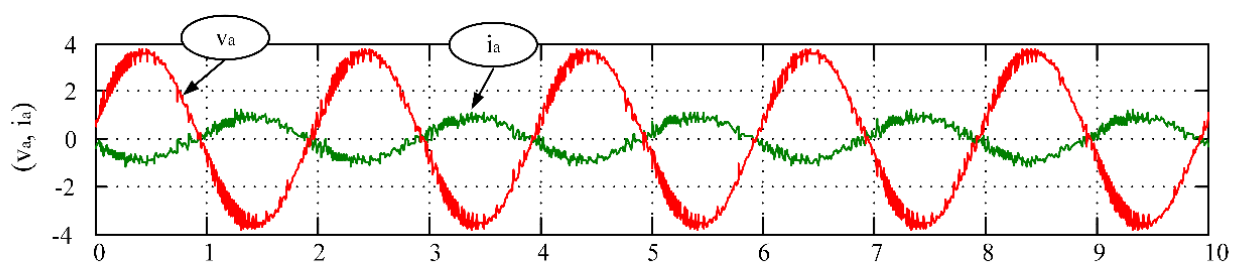

(e) The relationship between current and voltage

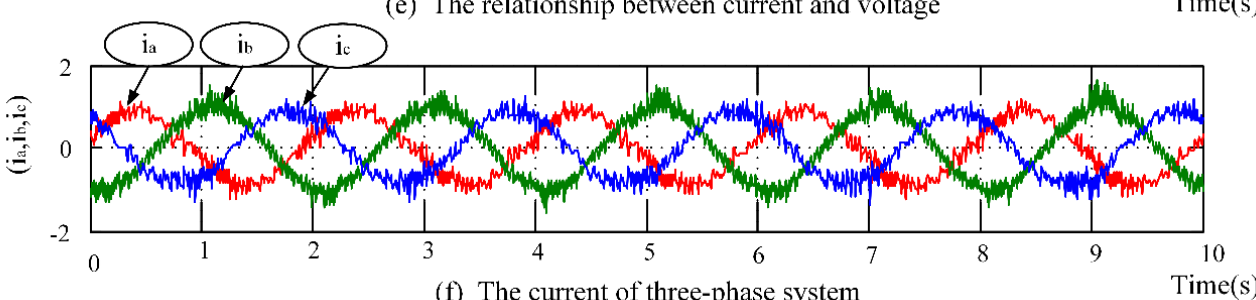

(f) The current of three-phase system

Figure 11. Step change of active power reference at $200 \mathrm{w}$ and $400 \mathrm{w}$ tuning gains by GSA-ANN

Figure 11(a), (b) demonstrates the step change of active power reference at $200 \mathrm{w}$ to $400 \mathrm{w}$ tuning gains by GSA-ANN. Where the red signal is a reference power and the green signal is the PI controller's behaviour. The obtained result shown that, there is an overshoot appearing in the system tested. This is due to the green signal that controlled the PI controller and risen up over than red signal obviously. This considered that the result is unacceptable condition. Figure 11(c) presents the flow of actual power, according to the control system. This case controls to be a value of zero. While Figure 11(d) also presents the flow of actual power, according to the control system from the provincial electricity authority's grid system to the load and it flows out from the inverter mode into the grid system. Moreover, Figure 11(e) presents the relationship between current and voltage phase angles at the stable load. It is found that the current phase angle has a slightly lagging of the voltage phase angle. Finally, Figure 11(f) summarizes the actual electricity of three-phase system such as phase $\mathrm{a}, \mathrm{b}$ and $\mathrm{c}$.

Figure 12 and Figure 13 show the values of total harmonic spectra of line current to the grid system of power of $200 \mathrm{w}$ and $400 \mathrm{w}$ and power factor value using a power quality analyzer on FLUKE model 43B. 


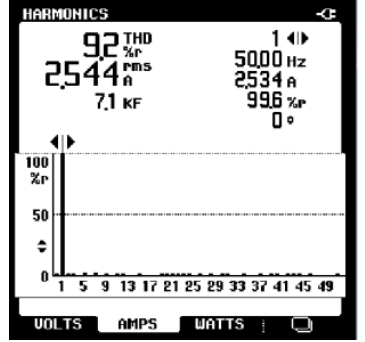

(a) THDi at step 0-200 w

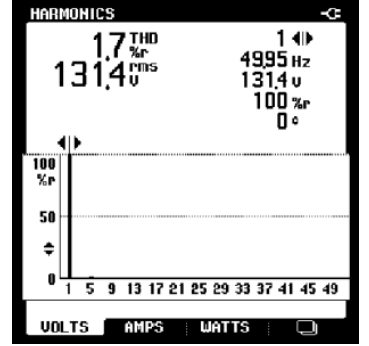

(b) THDV at step 0-200 w

Figure 12. Harmonic spectra of line current to grid system at power $200 \mathrm{w}$

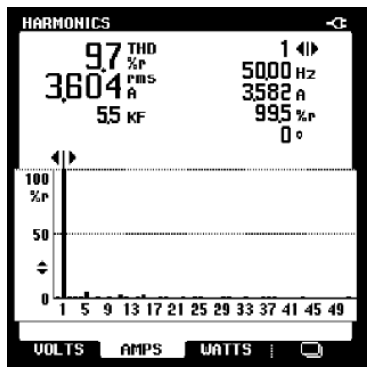

(a) THDi at step 0-400 w

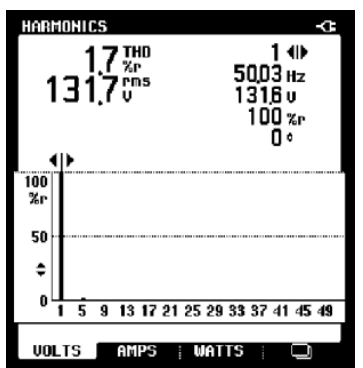

(b) THDV at step 0-400 w

Figure 13. Harmonic spectra of line current to grid system at power $400 \mathrm{w}$

\section{CONCLUSION}

In transmitting the electric power between wind turbine to the grid system of PEA of Thailand, the voltage transformation from three-phase to two-phase are based on $P-Q$ theory. The power is converted into the reference current on three-phase at 380 volts and $50 \mathrm{~Hz}$. The power flow of wind turbine system to threephase grid connected system is tested at $200 \mathrm{w}$ and $400 \mathrm{w}$. In this paper, the PI controller tuned by traditional method, pole placement method and artificial intelligent methods PSO, GSA and the combination those with artificial neural network, namely PSO-ANN and PSO-GSA, is proposed. The experimental results show that the overshoot of the proposed system that using PSO-ANN for tuning gains of PI controller is less than 5 percent of maximum overshoot and also the best response is the 10 percent to 90 percent rise time. As a consequence, the response of a proposed system controlled by PI controller tuned PSO-ANN method is better than pole placement, PSO, GSA and GSA-ANN methods. Therefore, the artificial intelligent tuning can provide the optimal gains for the PI controller, efficiently.

\section{ACKNOWLEDGMENTS}

This paper has been supported by Faculty of Electrical Engineering, Pathumwan Institute of Technology, Bangkok, Thailand and Faculty of Industrial Technology, ChiangRai Rajabhat University has provided the financial and facilities. Moreover, the authors thank for Assit.Dr.Wachirapond Permpoonsinsup's suggestions and recommendations.

\section{REFERENCES}

[1] J.R. Bumby, N. Stannard, J. Dominy, N. McLeod, "A permanent magnet generator for small scale wind And water turbines," in Proceedings of the International Conference on Electrical Machines, edited by IEEE, Vilamoura, Portugal, pp. 1-6, 2008.

[2] Wipobh Jaikhang, Puchong Chanjira, Satean Tunyasrirut, "Application of grid connected for wind turbine using PWM converter permanent magnet synchronous generator," Mathematics, Engineering \& Industrial Applications 2016 (ICoMEIA 2016) Conference on, Songkhla, Thailand, August 2016.

[3] Mohamed El-Shimy, Nisma Ghaly, "Wind Energy Conversion Systems, Grid-Connected," In Encyclopedia of Energy Engineering and Technology, Second Edition. Taylor and Francis, pp. 2162-2183, 2016.

[4] Sudheesh S, Daina Shaji, Jaison Cherian, "Wind Power Conversion System Using Hybrid Fuzzy-PI Controller for Doubly Fed Induction Generator," Novelty Journals Electrical and Mechanical Engineering, vol. 1, Issue 1, pp. 3243, 2014

[5] M. Arbaoui, A. Essadki, T. Nasser, and H. Chalawane, "Comparative analysis of ADRC \& PI controllers used in wind turbine system driving a DFIG," International Journal of Renewable Energy Research, vol. 7, no. 4, pp. 1816$1824,2017$.

IJEEI, Vol. 7, No. 4, Dec 2019: 703 - 719 
[6] Brahim Berbaoui, Chellali Benachaiba, Mustapha Rahli, Hamza Tedjini, "An efficient algorithm to tuning PIcontroller parameters for shunt active power filter using ant colony optimization," Przeglad Elektrotechniczny Electrical Review, ISSN 0033-2097, pp.140-145, 2011.

[7] B. Shyam, Aswathy B.Raj and P.C. Thomas, "An Efficient PMG based Wind Energy Conversion System with Power Quality Improvement Features,” ACEEE Int. J. on Electrical and Power Engineering, Vols. 03, pp.41-44, 2012.

[8] B. Raghava Rao, N. Ram Mohan, "Power Control and Quality Management in DG Grid Interfaced Systems," International Journal of Application or Innovation in Engineering \& Management, Vols. 2, pp.335-342, 2013.

[9] Yi Tang, Poh Chiang Loh, Peng Wang, Fook Hoong Choo, Feng Gao, and Frede Blaabjerg, "Generalized Design of High Performance Shunt Active Power Filter With Output LCL Filter," IEEE Trans. on Industrial Electronics, Vols. 59, pp.1443-1452, 2012.

[10] Ali Raza, Zain Yousaf, Mohsin Jamil, Syed Omer Gilani, Ghulam Abbas, Muhammad Uzair, Saima Shaheen, Abdeldjabar Benrabah and Fajun Li, "Multi-Objective Optimization of VSC Stations in Multi-Terminal VSC-HVdc Grids, Based on PSO," IEEE Access, Vol. 6, pp. 62995-63004, Oct. 2018.

[11] Fernando M. de Oliveira, Sérgio A. Oliveira da Silva, Fábio R. Durand, Leonardo P. Sampaio, Vinícius D. Bacon and Leonardo B.G. Campanhol, "Grid-tied photovoltaic system based on PSO MPPT technique with active power line conditioning," IET Power Electron., Vol. 9, 1ss. 6, pp. 1180-1191, 2016.

[12] Mariammal Thirumeni and Deepa Thangavelusamy, "Design and analysis of hybrid PSO-GSA tuned PI and SMC controller for DC-DC Cuk converter," IET Circuits Devices Syst., Vol. 13, 1ss. 3, pp. 374-384, 2019.

[13] Alessandro Massi Pavan, Nadjwa Chettibi, Adel Mellit, Thomas Feehally, Andrew J. Forsyth and Rebecca Todd, "ANN-based grid voltage and frequency forecaster," The Journal of Engineering Vol. 2019, 1ss. 17, pp. 3687-3691, 2019.

[14] Safdar Raza, Hazlie Mokhlis, Hamzah Arof, Kanendra Naidu, Javed Ahmed Laghari and Anis Salwa Mohd Khairuddin, "Minimum-features-based ANN-PSO approach for islanding detection in distribution system," IET Renew. Power Gener., Vol. 10, lss. 9, pp. 1255-1263, 2016.

[15] Ali Muhtar, I Wayan Mustika and Suharyanto, "The Comparison of ANN-BP and ANN-PSO as Learning Algorithm to Track MPP in PV System," The 7th International Annual Engineering Seminar (InAES), Yogyakarta, Indonesia, edited by IEEE, 2017.

[16] Edson H. Watanabe, Maurício Aredes and Hirofumi Akagi, "The P-Q theory for active filter control: some problems and solutions," Revista Controle \& Automaça ${ }^{a}$, Vol. 15, no.1, pp. 78-84, 2004.

[17] Ned Mohan, Advanced Electric Drives: Analysis, Control, and Modeling using MATLAB/Simulink (Hardback), John Wiley \& Sons Inc, United States, 2014

[18] Andrzej M. Trzynadlowski, Control of Induction Motors, Academic Press, 2001.

[19] Hirofumi Akagi, Edson Hirokazu Watanabe and Mauricio Aredes, "Instantaneous power theory and applications to power conditioning," Mohamed E. EI-Hawary, Series Editor, Wiley-Interscience A John Wiley \& Sons, Inc., Publication, pp. 4-102, 2007.

[20] Adam Milczarek, Mariusz Malinowski, "Monitoring and control algorithms applied to small wind turbine with gridconnected/stand-alone mode of operation," Przeglad Elektrotechniczny, Vol. 88, pp. 18-22, 2012.

[21] Aidan O'Dwyer, “Handbook of PI and PID Controller Tuning Rules, ” Imperial College Press, London, pp. 92-93. 2016.

[22] Tan Kok Kiong, Wang Qing-Guo and Hang Chang Chieh, Advances in PID Control, pp.2-262, 1999.

[23] A. Salem, M. A. Moustafa Hassan, M. E. Ammar, "Tuning PID Controllers Using Artificial Intelligence Techniques Applied To DC-Motor and AVR System," Asian Journal of Engineering and Technology. vol. 02, Issue 02, pp.129138, 2014.

[24] Said M. Mikki and Ahmed A. Kishk, Particle Swarm Optimization: A Physics-Based Approach, A Publication in the Morgan \& cLaypool publishers series, pp.1-103, 2008.

[25] Maureen Caudill, "Neural Network Primer : Part 1,” AI Expert. vol. 2, pp. 46-52, 1987.

[26] Wachiraporn Permpoonsinsup and Dusadee Sukawat, "Regional climate change downscaling by artificial neural network," The Third KMITL-TKU Joint International Symposium on Mathematics and Applied Mathematics, pp. 1623, 2012.

[27] T. Chai and R. R. Draxler, "Root mean square error (RMSE) or mean absolute error (MAE)?-Arguments against avoiding RMSE in the literature," Geosci. Model Dev., 7, pp. 1247-1250, 2014 